\title{
A integração de TDICs na prática de ensino de professores de línguas estrangeiras: análise do conhecimento tecnológico pedagógico
}

\author{
Michelli de Godoy Del Monico \\ Universidade Estadual Paulista - FCLar \\ michelligdm@hotmail.com
}

Cibele Cecílio de Faria Rozenfeld Universidade Estadual Paulista - FCLar cibeleroz@hotmail.com

\begin{abstract}
Resumo
Acreditando que a integração de tecnologias digitais de informação e comunicação (TDICs) na prática de ensino dos professores de línguas estrangeiras é necessária, utilizamos o modelo TPACK, que propõe a integração dos conhecimentos tecnológico e pedagógico no ensino, para verificar em que medida os professores conseguiram utilizar as TDICs de forma adequada ao modelo TPACK em seus planos de aulas. O curso: "O uso de novas e velhas tecnologias em sala de língua estrangeira (NoVeTeLe)" foi ofertado como extensão para professores, em um ambiente virtual (Moodle), sendo mediado por três docentes formadores. Como atividade final, foi proposta a elaboração de planos de aulas que incluíssem as TDICs na prática de ensino. Fizemos, portanto, uma análise qualitativa e indutiva desses planos de aulas de acordo com o modelo TPACK para sabermos como os professores utilizaram a integração dos conhecimentos. Os resultados mostraram que ainda existe uma deficiência em incluir as ferramentas tecnológicas em sala de aula.
\end{abstract}

Palavras-chave: TPACK. TDIC. Ensino de línguas.

\begin{abstract}
Believing that the integration of digital information and communication technologies (DICTs) in the teachers practice of teaching a foreign language is necessary, it was used the TPACK model, which proposes the integration of technological and pedagogical knowledge in teaching to check to what extent the teachers were able to use the DICTs properly in their lesson plans. The
\end{abstract}


course: "the use of new and old technologies in a foreign language class (NoVeTeLe)" was offered as an extension course to teachers in a virtual environment (Moodle), being mediated by three trainers teachers. As a final activity, it was proposed to develop lesson plans that included the DICTs in teaching practice. Therefore, we did a qualitative and inductive analysis of these lesson plans according to the model TPACK to know how the teachers used the integration of technological and pedagogical knowledge. The results showed that there is still a deficiency when including technological tools in the class.

Keywords: TPACK; DICTs; Language teaching.

\section{Introdução}

A situação escolar brasileira aponta reconhecidamente para a grande necessidade de se transformar a educação no país. De acordo com Koehler e Mishra (2009), fatores sociais e institucionais muitas vezes não dão suporte aos esforços dos professores para integrar o uso da tecnologia em seu trabalho, podendo até dificultar as relações entre ensino e tecnologias contemporâneas. Conforme postula Ribeiro (2004), a mudança nas práticas educacionais envolve, além de políticas públicas, necessariamente a figura do professor, pois é a partir de sua atuação que a mudança pode tornar-se realidade. Portanto, de acordo com os argumentos dos autores, é necessário que sejam feitas mudanças, tanto em aspectos sociais e institucionais quanto na formação dos professores.

De acordo com Lima (2013), a construção de conhecimento por meio de recursos tecnológicos contemporâneos pode possibilitar a superação de limites, a inclusão de discentes com deficiências e a aprendizagem significativa e colaborativa, mediada pela ação docente. Para tanto, a autora afirma ser necessário que haja iniciativa, inovação metodológica e criatividade.

Porém, conforme postulam diversos autores como Araújo (2004), não é suficiente introduzir as mídias na educação apenas para acompanhar o desenvolvimento tecnológico: é necessário que haja uma preparação para que os professores tenham segurança, não apenas em utilizá-las, mas em saber usá-las de modo seguro e satisfatório, transformando-as em aliadas para a aprendizagem. 
Além de uma formação adequada para a inserção de multimídias e tecnologias em sala de aula, é importante enfatizar a necessidade da organização de planejamentos de aula para uma utilização consciente e organizada de cada recurso midiático disponível, adequando-os aos componentes curriculares das diversas áreas do conhecimento (LIMA, 2013).

Diante do exposto, entendemos que o ensino de qualidade se definirá fortemente pelas ações do professor, que deve buscar atuar e auxiliar na formação de alunos críticos, participativos e reflexivos.

A proposta deste artigo nasce de reflexões tecidas ao longo de um programa para professores de línguas estrangeiras, realizado na modalidade a distância, que teve como intuito oferecer a possibilidade de formação para o uso de tecnologias digitais em sala de aula. $\mathrm{Na}$ seção 2 buscamos enfatizar a importância e a potencialidade das Tecnologias Digitais de Informação e Comunicação (TDICs) no ensino e aprendizagem de línguas. Na seção 3 apresentamos o programa e a forma com que os dados foram coletados e tratados para, na seção 4, apresentar uma análise da forma como as TDICs foram integradas em seus planos de aula e em que medida tais procedimentos de ensino se mostraram adequados a uma abordagem contemporânea de ensino ${ }^{1}$.

\section{Integração da tecnologia a processos educacionais}

As novas tecnologias podem reforçar a contribuição dos trabalhos pedagógicos e didáticos contemporâneos, pois permitem que sejam criadas situações de aprendizagens ricas, complexas e diversificadas (PERRENOUD, 2000).

De acordo com Moran (2004), para que a educação seja inovadora, é necessário desenvolver propostas com eixos que se

${ }^{1}$ Diante do escopo do trabalho, não nos estenderemos na discussão sobre as abordagens consideradas contemporâneas. Entendemos como tais aquelas que abarcam premissas da abordagem comunicativa (ALMEIDA FILHO, 1993; 2005) e pós-método (BROWN, 2012; KUMARAVADIVELU, 2003; 2006) amplamente discutida na literatura e que pressupõem, dentre outros aspectos, o aluno como participante do processo de aprendizagem, o contexto como único e a comunicação como foco de ensino. 
A integração de TDICs na prática de ensino de professores...

integrem, se complementem e se combinem. É necessário que tais eixos estejam focados em uma aprendizagem significativa e motivadora para os alunos. As tecnologias podem auxiliar na tarefa de motivar e despertar o interesse do aluno. No entanto, de acordo com Kenski (2005, p. 72, 73),

As tecnologias mais amplamente utilizadas - como o livro, os vídeos e a televisão - são recursos que ampliam o espaço da sala de aula, mas que não dispensam a realização de planejamentos. A simples apresentação de um filme ou programa de televisão - sem nenhum tipo de trabalho pedagógico anterior ou posterior à ação - desloca professores e alunos para uma forma receptiva e pouco ativa de educação. Uma forma também tradicional de educação ocorre em algumas atividades de ensino assistidas por computador. Embora a tecnologia seja avançada, a forma como é usada, em muitos casos, é bem convencional [...]. Os alunos, isolados, em interação exclusiva com o computador e o conteúdo, dispersam seus pensamentos. $O$ uso continuado e isolado da mídia cansa e os alunos logo desanimam. A preocupação da educação deve ir além.

No excerto, Kenski (2005) ressalta que há muitos casos em que ocorre um mau uso da tecnologia, de forma tradicional expositiva, sem o uso em sua potencialidade inovadora. Da mesma forma, Ertmer et al. (2009) acreditam que, para que o professor integre a tecnologia em sua prática de maneira adequada, são necessárias mudanças em quatro dimensões: conhecimento tecnológico, confiança, crenças pedagógicas e cultura escolar.

Por sua vez, os autores Koehler e Mishra (2009) propõem um modelo que integra formação de professores para promoção de conhecimento de conteúdo, tecnológico e pedagógico, conhecido como Technological Pedagogical Content Knowledge (TPACK) ou Conhecimento Tecnológico-Pedagógico de Conteúdo, representado na Figura 1. 


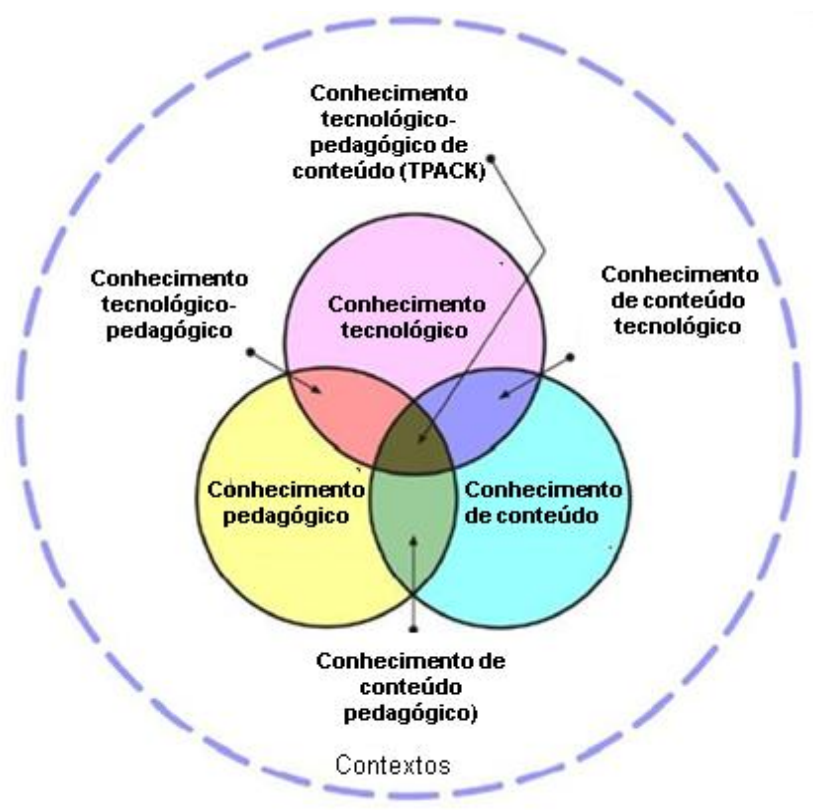

Figura 1: O modelo TPACK (KOEHLER; MISHRA, 2009). (tradução nossa)

O modelo TPACK foi construído com base nas descrições de Conhecimento de Conteúdo Pedagógico (PCK: Pedagogical Content Knowledge), de Shulman's (1987 apud Koehler e Mishra, 2009), para propor uma forma de compreensão dos tipos de conhecimento que devem estar envolvidos na prática docente. O ensino é caracterizado pela diversidade de situações que ocorrem em sala de aula e por uma inter-relação entre prática e teoria. No entanto, é necessário que o professor desenvolva determinados conhecimentos, descritos no modelo TPACK e aplicáveis a diversas situações.

De acordo com os autores Koehler e Mishra (2009), existem três componentes principais do conhecimento dos professores: de conteúdo, pedagógico e de tecnologia. Igualmente importantes são as interações entre esses conhecimentos, representados como:

1) Conhecimento de Conteúdo Pedagógico (PCK): é o conhecimento que o professor possui sobre a forma de ensinar determinado conteúdo aos alunos;

Horizontes de Linguística Aplicada, ano 15, n. 2, 2016 
A integração de TDICs na prática de ensino de professores...

2) Conhecimento de Conteúdo Tecnológico (TKC: Technological Content Knowledge): diz respeito ao domínio sobre o uso das ferramentas tecnológicas disponíveis para o uso de professores e alunos para o ensino e aprendizagem de determinado conteúdo de que se tem igualmente conhecimento;

3) Conhecimento Tecnológico-Pedagógico (TPK: Technological Pedagogical Knowledge): engloba o conhecimento acerca da potencialidade didático-pedagógica de determinadas ferramentas tecnológicas. Destacamos que tal conhecimento será central em nossas análises. Na união de todos os conhecimentos supracitados tem-se o modelo TPACK, que dever nortear a formação e a atuação do professor.

Em consonância com a proposta dos autores, utilizaremos neste trabalho o modelo TPACK para avaliar em que medida os docentes fizeram uso do conhecimento tecnológico e pedagógico, uma vez que partiremos do pressuposto de que existe conhecimento de conteúdo.

\section{Procedimentos metodológicos: o curso e a análise dos dados}

O curso em foco neste trabalho foi ofertado como extensão a distância, em um ambiente virtual na plataforma Moodle, contou com a participação de 32 professores de diferentes línguas estrangeiras - 17 deles em formação inicial e 15 em formação continuada - e teve duração de nove semanas. Ele foi mediado por três professores formadores, que dividiram funções ao longo do trabalho no ambiente virtual. Destaca-se que os participantes assinaram uma autorização permitindo o uso de seus dados e a enviaram via plataforma do curso ofertado. Optamos por utilizar a nomenclatura "Aluno 1, 2, 3,..." para ser mantido o anonimato durante todo o processo de análise.

Conforme mencionamos, o objetivo central do programa foi discutir o uso de TDICs em sala de aula de LE (título do curso: "O uso de novas e velhas tecnologias em sala de aula de língua estrangeira" NoVeTeLE). 
Quadro 1: Temas dos módulos do curso

\begin{tabular}{|c|c|c|c|}
\hline Módulo & Título & Módulo & Título \\
\hline 1 & $\begin{array}{l}\text { Apresentação do grupo: } \\
\text { Conhecendo o ambiente do } \\
\text { curso. }\end{array}$ & 6 & $\begin{array}{l}\text { Banco de ideias: ferramentas } \\
\text { digitais para o ensino e } \\
\text { aprendizagem de LE. }\end{array}$ \\
\hline 2 & $\begin{array}{l}\text { Somos antes de tudo } \\
\text { educadores. (Reflexões } \\
\text { acerca de pressupostos de } \\
\text { Freire e Vygostky) }\end{array}$ & 7 & $\begin{array}{l}\text { Planejamento de aulas: usando } \\
\text { TDICs em sala de aula. }\end{array}$ \\
\hline 3 & $\begin{array}{l}\text { Do códex à cibercultura: } \\
\text { sobre novas e velhas } \\
\text { tecnologias. (Discussão } \\
\text { sobre mudanças } \\
\text { ocasionadas no } \\
\text { comportamento de leitura e } \\
\text { escrita desde a invenção da } \\
\text { imprensa até a chamada } \\
\text { "cibercultura") }\end{array}$ & 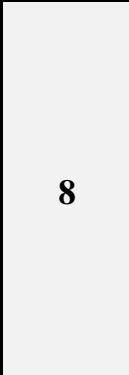 & $\begin{array}{l}\text { Elaboração de trabalhos de } \\
\text { finalização de curso. } \\
\text { Elaboração e entrega } \\
\text { dos planejamentos de aulas }\end{array}$ \\
\hline 4 & $\begin{array}{l}\text { As Tecnologias Digitais de } \\
\text { Informação e Comunicação } \\
\text { (TDICs) em sala de aula de } \\
\text { LE. }\end{array}$ & 9 & Avaliação do curso \\
\hline 5 & $\begin{array}{l}\text { Objetos de aprendizagem: } \\
\text { pesquisando o termo e os } \\
\text { repositórios. }\end{array}$ & & \\
\hline
\end{tabular}

Fonte: Quadro nosso 
A integração de TDICs na prática de ensino de professores...

Na Figura 2 apresentamos um recorte da página de entrada no ambiente do curso.

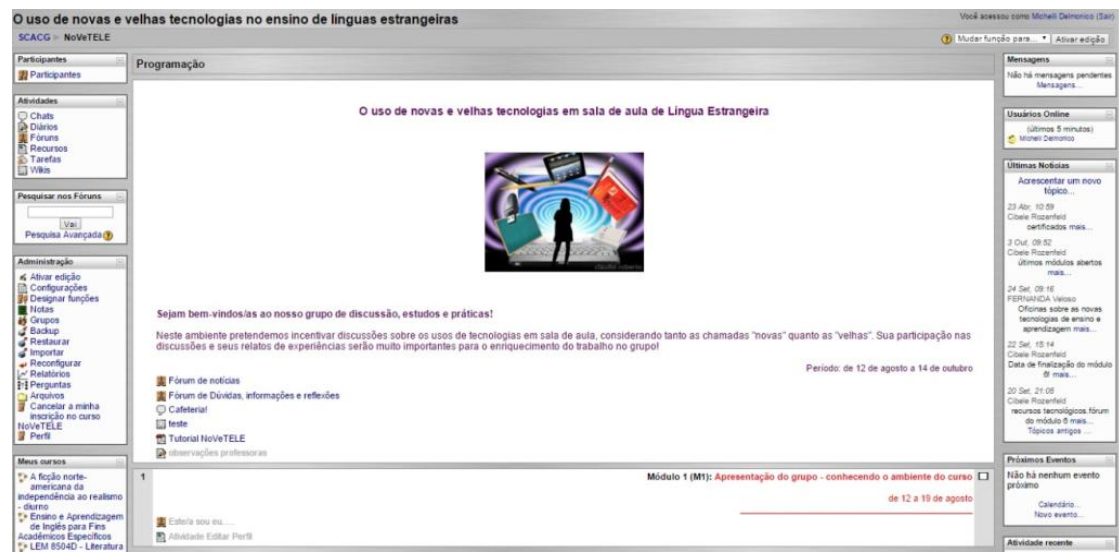

Figura 2: Recorte da tela inicial do curso NoVeTeLe

Para a elaboração da atividade final do curso foi solicitada a leitura de um texto ${ }^{2}$ que descreve o planejamento de aula em fases (ROZENFELD; VIANA, 2006) e pedido aos professores que estruturassem um plano de aula que contemplasse as seguintes informações e descrições: 1) indicação do nível e do contexto do grupo; 2) definição dos objetivos gerais, comunicativos e linguísticos; 3) descrição das atividades realizadas nas diferentes fases da aula descritas pelos autores, a saber, introdução, preparação do insumo, apresentação, compreensão, fixação, transferência, uso livre e fechamento, bem como os procedimentos, os recursos utilizados, a forma de organização social (expositiva, individual, grupo ou duplas) e o tempo previsto em cada uma delas. ${ }^{3}$

Dos 25 professores inscritos no início do curso, apenas 12 o finalizaram e entregaram os planos de aula, os quais foram analisados minuciosamente para o desenvolvimento deste trabalho. Conforme mencionado anteriormente, para analisar os planos de aula, baseamonos prioritariamente no conceito de conhecimento tecnológico-

${ }^{2}$ Texto disponível em: <http://www.abrapa.org.br/cd/npdfs/RotzenfeldViana.pdf>. Acesso em: 09 fev. 2016. 
pedagógico proposto por Koehler e Mishra (2009). Utilizamos o método qualitativo para analisar as informações dos planos de aula de forma organizada e verificar a relação da realidade com o objeto de estudo, ou seja, a relação entre os planos de aula com o modelo TPACK, obtendo, assim, algumas interpretações dentro de uma análise indutiva.

Ao longo de nossas análises, buscamos encontrar categorias que indicassem se houve inserção de recursos apresentados no programa e se eles foram inseridos de forma adequada. Para considerar tal adequação, tomamos as premissas das abordagens comunicativa e pós-método como aquelas que correspondem ao bom conhecimento pedagógico dos professores ${ }^{4}$.

Tendo em vista o foco deste trabalho, debruçaremo-nos prioritariamente na relação entre o conhecimento tecnológico e pedagógico proposto no modelo TPACK. Do cruzamento de tais dados, elaborou-se a lista de critérios apresentada no Quadro 2.

\section{Quadro 2: Níveis de uso das TDICs de acordo com o modelo TPACK}

Nível 1 - Não há uso de tecnologias digitais de informação e comunicação (TDICs) no trabalho com o conteúdo.

Nível 2 - Há o uso de algumas TDICs no trabalho com o conteúdo, porém de modo apenas expositivo (práticas tradicionais, baixo nível de conhecimento pedagógico).

Nível 3 - Há o uso de algumas TDICs no trabalho com o conteúdo, com atividades interativas, mas executadas de forma expositiva, com pouca participação dos alunos.

Nível 4 - Há um uso de TDICs mais diversificadas no trabalho com o conteúdo, com participação dos alunos e práticas mais contemporâneas de ensino.

Nível 5 - Há o uso de TDICs diferenciadas em sala de aula, relacionando de maneira bastante satisfatória tecnologia à prática pedagógica, incluindo participação dos alunos, e práticas inovadoras e contemporâneas de ensino.

Fonte: Quadro nosso

${ }^{4}$ Ver em nossa primeira nota de rodapé nossos pressupostos sobre tais premissas.

Horizontes de Linguística Aplicada, ano 15, n. 2, 2016 
A integração de TDICs na prática de ensino de professores...

Com base em tais critérios, os planos de aula foram analisados e são apresentados na seção 6.

\section{0 conhecimento tecnológico-pedagógico presente nas atividades propostas}

Foi feita uma tabela com os resumos dos planos de aula de acordo com o uso das TDICs, juntamente com a separação dos níveis do modelo TPACK, para que possamos fazer uma análise, pensando em que medida esses professores utilizaram as TDICs em seus planos de aula.

Quadro 3: Resumo dos planos de aula

\begin{tabular}{|c|c|c|c|c|}
\hline Aluno & $\begin{array}{c}\text { Conteúdo/ } \\
\text { tema }\end{array}$ & $\begin{array}{l}\text { Materiais } \\
\text { utilizados }\end{array}$ & $\begin{array}{l}\text { Uso da } \\
\text { tecnologia }\end{array}$ & $\begin{array}{l}\text { Uso das } \\
\text { TDICs }\end{array}$ \\
\hline 1 & $\begin{array}{l}\text { Viagens. O } \\
\text { tempo verbal: } \\
\text { futuro; os } \\
\text { meios de } \\
\text { transporte. }\end{array}$ & $\begin{array}{l}\text { Lousa, } \\
\text { gravuras; } \\
\text { livro, DVD, } \\
\text { vídeo, } \\
\text { computador, } \\
\text { projetor, etc. }\end{array}$ & $\begin{array}{l}\text { Expositivo: usa o } \\
\text { projetor para } \\
\text { destacar os verbos } \\
\text { que estão } \\
\text { conjugados no } \\
\text { futuro e mostrar } \\
\text { as imagens dos } \\
\text { meios de } \\
\text { transporte } \\
\text { utilizados na } \\
\text { França. }\end{array}$ & Nível 2 \\
\hline 2 & $\begin{array}{l}1^{\mathrm{a}} \text { aula: } \\
\text { alfabeto da } \\
\text { língua inglesa. }\end{array}$ & $\begin{array}{l}\text { Lousa, cartaz, } \\
\text { gravuras, } \\
\text { livro, CD, } \\
\text { DVD, vídeo, } \\
\text { computador, } \\
\text { projetor. }\end{array}$ & $\begin{array}{l}\text { Utiliza vídeo do } \\
\text { alfabeto; propõe } \\
\text { uma atividade de } \\
\text { jogo no } \\
\text { computador. }\end{array}$ & Nível 4 \\
\hline 3 & $\begin{array}{l}\text { Características } \\
\text { físicas e } \\
\text { psicológicas } \\
\text { em língua } \\
\text { espanhola. }\end{array}$ & $\begin{array}{l}\text { Lousa, cartaz, } \\
\text { gravuras, } \\
\text { livro, CD, } \\
\text { DVD, vídeo, } \\
\text { computador, }\end{array}$ & $\begin{array}{l}\text { Utiliza o } \\
\text { computador para } \\
\text { passar o filme: } O \\
\text { labirinto do } \\
\text { fauno. }\end{array}$ & Nível 2 \\
\hline
\end{tabular}


Michelli G. Del Monico; Cibele C. F. Rozenfeld

\begin{tabular}{|c|c|c|c|c|}
\hline & & projetor. & & \\
\hline 4 & $\begin{array}{l}\text { ¡SALUDOS! } \\
- \\
\text { Cumprimentar } \\
\text { e despedir. }\end{array}$ & $\begin{array}{l}\text { Lousa, cartaz, } \\
\text { gravuras, } \\
\text { livro, CD, } \\
\text { DVD, vídeo, } \\
\text { computador, } \\
\text { projetor. }\end{array}$ & $\begin{array}{l}\text { Exposição: usa o } \\
\text { projetor para } \\
\text { destacar maneiras } \\
\text { de cumprimentar } \\
\text { e despedir-se } \\
\text { formal e } \\
\text { informalmente. }\end{array}$ & Nível 2 \\
\hline 5 & $\begin{array}{l}\text { Discurso } \\
\text { direto } \\
\text { (revisão) e } \\
\text { indireto. }\end{array}$ & $\begin{array}{l}\text { Lousa, cartaz, } \\
\text { gravuras, } \\
\text { livro, vídeo, } \\
\text { projetor, } \\
\text { computador, } \\
\text { Googledocs. }\end{array}$ & $\begin{array}{l}\text { Aula expositiva } \\
\text { com slides e } \\
\text { utilização de um } \\
\text { vídeo de uma } \\
\text { música do } \\
\text { Youtube; sendo a } \\
\text { reescrita dessa } \\
\text { música do } \\
\text { discurso direto } \\
\text { para o indireto } \\
\text { (vice-versa) } \\
\text { realizada em } \\
\text { grupo e no } \\
\text { computador por } \\
\text { meio do } \\
\text { Googledocs. }\end{array}$ & Nível 2 \\
\hline 6 & $\begin{array}{l}\text { Uso de } \\
\text { pronomes e } \\
\text { adjetivos } \\
\text { possessivos } \\
\text { em espanhol. }\end{array}$ & $\begin{array}{l}\text { Lousa, cartaz, } \\
\text { gravuras, } \\
\text { livro, vídeo, } \\
\text { computador, } \\
\text { projetor. }\end{array}$ & $\begin{array}{l}\text { Os alunos devem } \\
\text { elaborar tirinhas } \\
\text { com alguma } \\
\text { história curta que } \\
\text { envolva a família } \\
\text { (site: } \\
\text { http://stripgenerat } \\
\text { or.com/strip/creat } \\
\text { e/), usando os } \\
\text { possessivos. Há } \\
\text { ainda um trailer } \\
\text { de um filme no } \\
\text { Youtube. }\end{array}$ & Nível 5 \\
\hline 7 & $\begin{array}{l}\text { Going places } \\
\text { (Time clauses } \\
\text { - IF - hot } \\
\text { verbs }\end{array}$ & $\begin{array}{l}\text { Lousa, cartaz, } \\
\text { gravuras, } \\
\text { livro, CD, } \\
\text { DVD, vídeo, }\end{array}$ & $\begin{array}{l}\text { Explicitação de } \\
\text { "If clauses" em } \\
\text { uma aula } \\
\text { expositiva no }\end{array}$ & Nível 2 \\
\hline
\end{tabular}

Horizontes de Linguística Aplicada, ano 15, n. 2, 2016 
A integração de TDICs na prática de ensino de professores...

\begin{tabular}{|c|c|c|c|c|}
\hline & $\begin{array}{l}\text { make/do/ } \\
\text { take/get - } \\
\text { directions). }\end{array}$ & $\begin{array}{l}\text { computador, } \\
\text { projetor. }\end{array}$ & computador. & \\
\hline 8 & $\begin{array}{l}\text { Imperativo e } \\
\text { modalização } \\
\text { comunicativa. }\end{array}$ & $\begin{array}{l}\text { Lousa, cartaz, } \\
\text { gravuras, } \\
\text { livro, vídeo, } \\
\text { projetor, } \\
\text { computador. }\end{array}$ & $\begin{array}{l}\text { Apresentação de } \\
\text { vídeos (Youtube) } \\
\text { retirados de } \\
\text { filmes contendo o } \\
\text { uso do imperativo } \\
\text { como exemplos } \\
\text { de reforço } \\
\text { contextual. }\end{array}$ & Nível 2 \\
\hline 9 & $\begin{array}{l}\text { Intertextualida } \\
\text { de. }\end{array}$ & $\begin{array}{l}\text { Lousa, cartaz, } \\
\text { gravuras, } \\
\text { livro, vídeo, } \\
\text { projetor, } \\
\text { computador, } \\
\text { blog. }\end{array}$ & $\begin{array}{l}\text { Utiliza o } \\
\text { computador para } \\
\text { mostrar vídeos; } \\
\text { sugere que os } \\
\text { textos feitos pelos } \\
\text { alunos deverão } \\
\text { ser postados em } \\
\text { um blog. }\end{array}$ & Nível 5 \\
\hline 10 & $\begin{array}{l}\text { Análise do } \\
\text { filme Volver, } \\
\text { de Pedro } \\
\text { Almodóvar. }\end{array}$ & $\begin{array}{l}\text { Lousa, livro, } \\
\text { vídeo, } \\
\text { projetor, } \\
\text { computador, } \\
\text { câmera, } \\
\text { facebook. }\end{array}$ & $\begin{array}{l}\text { Utiliza o } \\
\text { computador para } \\
\text { mostrar o filme; } \\
\text { votação no } \\
\text { facebook para os } \\
\text { alunos escolherem } \\
\text { o melhor vídeo } \\
\text { feito por eles } \\
\text { encenando trechos } \\
\text { do filme. }\end{array}$ & Nível 5 \\
\hline 11 & $\begin{array}{l}\text { Atividades de } \\
\text { tempo livre. }\end{array}$ & $\begin{array}{l}\text { Lousa, cartaz, } \\
\text { gravuras, } \\
\text { livro, vídeo, } \\
\text { projetor, } \\
\text { computador. }\end{array}$ & $\begin{array}{l}\text { Utiliza vídeo no } \\
\text { Youtube e propõe } \\
\text { atividade em que } \\
\text { os alunos devem } \\
\text { elaborar um } \\
\text { Glogster (o } \\
\text { Glogster é uma } \\
\text { rede social que } \\
\text { permite aos } \\
\text { utilizadores a } \\
\text { criação de }\end{array}$ & Nível 5 \\
\hline
\end{tabular}

Horizontes de Linguística Aplicada, ano 15, n. 2, 2016 
Michelli G. Del Monico; Cibele C. F. Rozenfeld

\begin{tabular}{|l|l|l|l|l|}
\hline & & $\begin{array}{l}\text { cartazes } \\
\text { interativos } \\
\text { gratuitos ou } \\
\text { glogs) com o } \\
\text { resultado final de } \\
\text { suas pesquisas. }\end{array}$ & \\
\hline $\mathbf{1 2}$ & $\begin{array}{l}\text { Próximas } \\
\text { férias. }\end{array}$ & $\begin{array}{l}\text { Lousa, cartaz, } \\
\text { gravuras, } \\
\text { livro, vídeo, } \\
\text { projetor, } \\
\text { computador. }\end{array}$ & $\begin{array}{l}\text { Utilização de um } \\
\text { vídeo do Youtube. }\end{array}$ & Nível 2 \\
\hline
\end{tabular}

Fonte: Quadro nosso

Considerando no Quadro 3 os dados da terceira e da quarta coluna (materiais utilizados e uso da tecnologia), nota-se a presença de materiais e ferramentas que não foram de fato utilizados em aula. Muitos usaram apenas o computador (com Datashow), lousa e vídeos.

$\mathrm{O}$ aluno 1 (A1) criou um plano de aula sobre viagens e meios de transporte, optando por utilizar como tempo verbal o futuro. Ministrou uma aula de maneira expositiva, na qual usou o projetor apenas para destacar os verbos que estavam conjugados e mostrar imagens dos meios de transporte utilizados na França. Por essa razão, consideramos que o nível 2 se adéque melhor, uma vez que há um conhecimento de conteúdo e também tecnológico, mas não há a presença de procedimentos pedagógicos adequados, na medida em que a função do projetor/datashow ficou restrita apenas à exposição de conteúdo, sem exploração de outras potencialidades didáticopedagógicas. Neste caso, o datashow assumiu o papel de uma lousa, por exemplo. Julgamos que, nessa situação, outros recursos, como por exemplo o Google Maps, blog, rede social, utilizados de forma interativa, ${ }^{5}$ poderiam se adequar melhor aos propósitos da aula e integrariam os conhecimentos tecnológico e pedagógico. Além disso, a

${ }^{5}$ Ao falarmos sobre interação e atividades interativas, referimo-nos a interações entre professor/aluno e aluno/aluno nas atividades realizadas por meio do computador.

Horizontes de Linguística Aplicada, ano 15, n. 2, 2016 
ênfase do trabalho ficou centrada apenas em estruturas gramaticais, acarretando um empobrecimento do material apresentado e da temática da aula.

O A2 preparou uma aula sobre o alfabeto para crianças e, além de ter mostrado um vídeo, propôs uma atividade de jogo no computador por meio do site da Nickelodeon (canal infantil) para que os alunos pudessem reconhecer as letras e seus respectivos sons. Dessa forma, a aula tornou-se mais prática e menos expositiva. Assim, entendemos que o professor/aluno A2 encontra-se no nível 4 do modelo TPACK, uma vez que incluiu atividades interativas, demonstrando, além de conhecimento tecnológico - que diz respeito ao domínio do uso das ferramentas tecnológicas -, conhecimento pedagógico, embora ainda com momentos expositivos, nos quais poderia ter sido feito algo mais interativo.

Os professores/alunos A3 e A4 fizeram uso de TDICs, mas apenas de forma expositiva; por essa razão, consideramos que ambos se encontram no nível 2, de acordo com o níveis do modelo TPACK: nota-se a presença de conhecimento tecnológico, mas inadequado em relação ao conhecimento pedagógico, visto que eles não elaboraram aulas em que a tecnologia estivesse integrada a práticas pedagógicas inovadoras.

O A5 criou uma aula expositiva sobre o tema discursos indireto e direto. Para tanto, utilizou uma música disponível no canal de vídeos Youtube e propôs como atividade a reescrita dessa música para o discurso indireto e direto por meio do Googledocs. Consideramos que a prática pode enquadrar-se no nível 2 , na medida em que ele apresenta uma aula mais expositiva e sem interação, propondo uma atividade por meio de uma TDIC.

O aluno A6 preparou uma aula sobre o uso de pronomes e adjetivos possessivos e propôs uma atividade em que os alunos deveriam usar a ferramenta Strip Generator (http://stripgenerator.com/strip/create/) para criar tirinhas usando os pronomes aprendidos. Por ter utilizado uma ferramenta nova e citada previamente no curso de extensão, além de ter feito uma aula pouco expositiva e mais interativa, consideramos que o professor utilizou conhecimentos relativos ao nível 5, na medida em que há um maior conhecimento tecnológico e pedagógico utilizados de forma apropriada dentro da sala de aula. 
Os alunos A7, A8 e A12 lançaram mão de conhecimentos do nível 2, na medida em que ministraram aulas expositivas (mais característica em abordagens tradicionais) por meio de slides e vídeos do Youtube (conhecimento tecnológico), ou seja, sem um conhecimento pedagógico maior inerente a práticas mais inovadoras.

O aluno A9 propôs como tema de sua aula a questão da intertextualidade. Utilizou o computador de forma pouco expositiva, sugerindo aos alunos que fizessem um texto que deveria ser postados no blog da turma. De acordo com essa atividade, consideramos que o professor se enquadra no nível 5 de uso da tecnologia, pois há uma integração da tecnologia na prática pedagógica do professor de forma interativa e com grande participação dos alunos.

O aluno A10 escolheu como tema da aula a análise do filme Volver, de Pedro Almodóvar. Ele propôs uma atividade em que os alunos deveriam encenar um trecho do filme, gravar e postar o vídeo na rede social Facebook para que os colegas pudessem eleger o melhor. Julgamos a atividade como resultado da integração dos vários conhecimentos, além de ser constituída de prática bastante inovadora, multimidiática, desafiadora e motivadora para os alunos. Nesse sentido, consideramos que ele se enquadre no nível 5, visto que, além de utilizar tecnologias contemporâneas, incitou discussões, fazendo com que os alunos participassem da aula, oferecendo pouco conteúdo de forma expositiva.

O aluno A11 usou como tema: "Atividades de tempo livre". Para esta aula, ele utilizou um vídeo no Youtube e propôs uma atividade em que os alunos imaginariam que eles haviam sido convidados por uma agência para participar de uma pesquisa sobre os hábitos dos brasileiros em seu tempo livre. Para isso, teriam de entrevistar seus colegas sobre as atividades praticadas durante o ócio e anotar suas respostas. Por fim, deveriam elaborar na ferramenta Glogster (rede social que permite aos usuários a criação de cartazes interativos gratuitos ou glogs) o resultado final de suas pesquisas. Dessa forma, julgamos que a atividade e a forma de trabalho se enquadra no nível 5, visto que a proposta envolve muita ação, interação, uso de uma ferramenta não familiar (apresentada durante o curso) e de forma adequada a perspectivas contemporâneas de ensino de línguas estrangeiras. 
A integração de TDICs na prática de ensino de professores...

Apresentamos na Figura 3 um gráfico para termos uma melhor visualização dos níveis de acordo com o modelo TPACK atribuídos às atividades dos planos de aula dos alunos/professores.

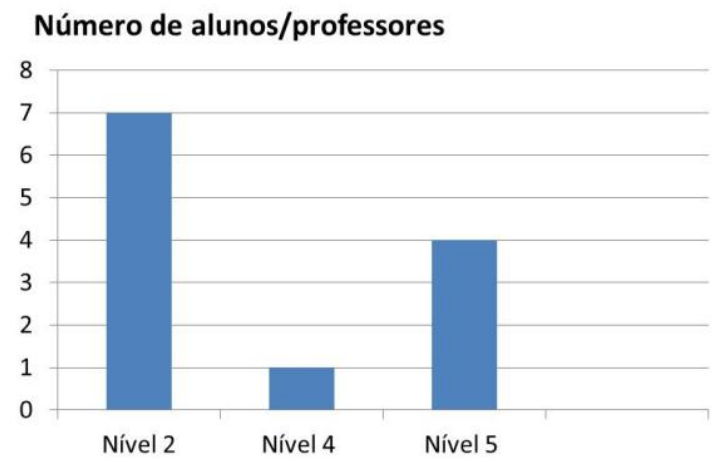

Figura 3: Relação número de alunos/professores

e nível de conhecimento tecnológico pedagógico.

Com base em nossas análises, concluímos que, embora alguns alunos/professores tenham feito uso de TDICs nas atividades propostas nos planos de aula, a maior parte não utilizou adequadamente a tecnologia em suas práticas pedagógicas, uma vez que a simples exposição da matéria por meio de tecnologia digital, sem a participação dos alunos e prática inovadora, não pode ser vista como um uso satisfatório da tecnologia. De acordo com o gráfico, podemos perceber que apenas quatro alunos utilizaram os conhecimentos tecnológico e pedagógico integrados de forma satisfatória em seus planos de aula.

\section{Conclusão}

É notável a necessidade de os professores incluírem a tecnologia em suas práticas pedagógicas. Apesar de os professores terem discutido a importância do uso das TDICs em sala de aula e conhecido algumas delas de forma mais prática, a maioria utilizou apenas aquelas que lhes eram familiares. Nota-se, assim, certa dificuldade dos docentes para integrar as TDICs no plano de aula de

Horizontes de Linguística Aplicada, ano 15, n. 2, 2016 
maneira condizente com abordagens contemporâneas de ensino. Não pretendemos com este trabalho tecer generalizações, mas discutir resultados que nos dão indícios de uma tendência de professores de, apesar do uso de tecnologias contemporâneas, utilizar práticas tradicionais em sala de aula.

O uso de mídias por si só não é suficiente para que seja feito um ensino em consonância com uma nova proposta de aprendizagem de línguas, que inclua diversas atividades online por meio de ferramentas que estão presentes, especialmente, no cotidiano dos mais jovens.

Assim, postulamos a necessidade de novos cursos de formação de professores para que eles estejam aptos a usar as TDICs dentro da sala de aula em conformidade com práticas inovadoras, visando tanto facilitar o aprendizado quanto incitar o interesse dos alunos, motivando-os a aprender uma língua estrangeira.

Nos planos de aula do curso analisado, há uma ausência de tópicos sobre as diferentes abordagens de ensino e elaboração de planos de aula. Portanto, finalizamos sugerindo que programas de formação de professores para o uso de TDICs incluam em seus programas leituras e discussões mais aprofundadas sobre tais temas. Assim, defendemos a necessidade de programas de formação de professores para uso de TDICs enfatizarem não apenas o conhecimento tecnológico (das ferramentas) e as teorias inerentes a este aspecto, mas também estudos acerca de metodologias de ensino de línguas estrangeiras, uma vez que o foco do ensino de muitos professores ainda recai fortemente sobre a gramática e de forma expositiva.

\section{Referências}

ALMEIDA FILHO, J. C. P. Dimensões comunicativas no ensino de línguas. Campinas: Pontes Editores, 1993. 74p.

(Org.) O professor de língua estrangeira em formação. Campinas: Pontes Editores, 2005. 184p.

ARAÚJO, M. I. Uma abordagem sobre as tecnologias da informação e da comunicação na formação do professor. In: MERCADO, L.; 
A integração de TDICs na prática de ensino de professores...

KULLOK, M. Formação de professores: política e profissionalização. Maceió: Edufal, 2004.

BROWN, H. D. English Language teaching in the Post-Methode Era: toward better diagnosis, treatment and assessment. In: RICHARDS, J. C. RENANDYA, W. A. Methodology in language teaching: an anthology of current practice. Cambridge: CUP, 2002.

ERTMER, P. A. et al. Facilitating technology-enhanced PBL in the K12 classroom: an examination of how and why teachers adapt. International Journal of Learning Technology , v. 20, n. 1, p. 35-54, 2009.

KENSKI, V. M. Das salas de aula aos ambientes virtuais de aprendizagem. In: CONGRESSO NACIONAL DA EDUCAÇÃO A DISTÂNCIA, 12., 2005, Florianópolis. Disponível em:

<http://www.abed.org.br/congresso2005/por/pdf/030tcc5.pdf>. Acesso em: 31 dez. 2015.

KOEHLER, M. J.; MISHRA, P. What is technological pedagogical content knowledge. Contemporary Issues in Technology and Teacher Education, v. 9, n. 1, p. 60-70, 2009.

KUMARAVADIVELU, B. Beyong methods: macrostrategies form language teaching. New Haven; London: Yale University, 2003. p.2343.

Understanding language teaching: from method to postmethod. Mahwah, New Jersey: Lawrence Erlbaum Associates, Publishers, 2006, p.161-174

LIMA, M. F. Formação dos professores para a inserção das mídias em sala de aula: uma proposta de ação, reflexão e transformação. HOLOS, ano 29, v. 3, p. 100-110, 2013. Disponível em: <http://www2.ifrn.edu.br/ojs/index.php/HOLOS/article/viewFile/727/6 94>. Acesso em: 23 nov. 2016.

MORAN, J. M. A contribuição das tecnologias para uma educação inovadora. Contrapontos, v. 4, n. 2, p. 347-356, 2004. 
PERRENOUD, P. Dez novas competências para ensinar. Porto Alegre: Artmed, 2000.

RIBEIRO, R. Dez princípios sobre professores e formação de professores. Trajetórias e perspectivas da formação de educadores. São Paulo: Editora Unesp, 2004. p. 120-126.

ROZENFELD, C. C. F.; VIANA, N. Planejamento de aula: uma reflexão sobre o papel do livro didático e as fases da aula. VI BRASILIANISCHER DEUTSCHLEHRERKONGRESS/I LATEINAMERIKANISCHER DEUTSCHLEHRERKONGRESS, 6., 2006. São Paulo. Anais... São Paulo, 2006.

ROZENFELD, C. C. F.; VELOSO, F. S. O uso de recursos digitais e os objetivos pedagógicos em planejamentos de aula: análise de consonâncias e dissonâncias em um curso para professores de línguas estrangeiras. CONGRESSO NACIONAL DE FORMAÇÃO DE PROFESSORES, 2., 2014. Águas de Lindóia. Anais...Águas de Lindóia, 2014

SHULMAN, L. S. Knowledge and teaching: foundations of the new reform. Harvard Educational Review, v. 57, n. 1, p. 1-27, 1987.

Recebido em: 14/07/2016 Aceito em: 11/10/2016

Title: The integration of DICTs in foreign language teachers' practice: an analysis of educational and technological knowledge 